\title{
¿Se puede aún hablar de poder espiritual? (Primera parte)*
}

\author{
Michel Serres
}

\author{
Traducción del francés al español de \\ Luis Alfonso Paláu-Castaño \\ Universidad Nacional de Colombia, Medellín, Colombia \\ laPalau@une.net.co
}

\begin{abstract}
A menudo me quejo de que, de joven, nunca tuve maestros. Comentando indefinidamente, los profesores de filosofía repetían. Los antiguos retomaban a Platón, Descartes y Kant por una revolución llamada heroica y de izquierda, los nuevos se pusieron a plagiar a Marx, Nietzsche y Freud por otra, conservadora y de derecha. Se dice que los competidores de aquellos últimos citarán a Heidegger y Wittgenstein, la escuela continental de Europa versus la escuela analítica de Estados Unidos. Decepción perenne, no se dejaba de plagiar. Qué pensaba ese mundo por sí mismo; misterio. Lanzarse uno completamente solo cuesta un precio infinito.
\end{abstract}

Divina sorpresa: una vez llegado a mi vejez, encuentro a sucesores que por fin ya no repiten, y a los que me hubiera gustado entonces convertir en mis predecesores. ¿Pero, por qué no recomenzar?

Acabo de leer muchas veces, con pasión, los diálogos que por instigación de Pasquale Gagliardi y Bruno Latour, los investigadores de la fuerza de Philippe Descola, François Jullien, Gilles Kepel, Derrick de Kerkhobe, Giovanni Levi, Sebastiano Maffetone, Angelo Scola, Isabelle Stengers, Peter Sloterdijk y Adam Zagajewski han tenido recientemente en la Fundazione Cini de Venecia. Un patriarca y once apóstoles, jóvenes, brillantes, originales, y en el puesto doce algunos heréticos contestatarios cuyas intervenciones, ruidosas y mudas, le añaden complacientemente una alevosía al grupo.

Concerniente a la política, quizás no haya en la actualidad un libro más leal, preciso, adaptado a nuestro tiempo, justo en el tono, apropiado para

* Cómo citar: Serres, M. (2019). ¿Se puede aún hablar de poder espiritual? (Primera parte). Ciencias Sociales y Educación, 8(15), 211-233. DOI: https://doi.org/10.22395/csye.v8n15a11

Agradecemos a Crítique por posibilitar la publicación de la traducción al español del texto del filósofo e historiador de las ciencias, Michel Serres. La traducción la realizó el profesor Luis Alfonso Paláu-Castaño en julio del 2011 y se publica por vez primera en la presente edición de la revista (nota del editor).

Recibido: 15 de febrero de 2019.

Aprobado: 5 de abril de 2019. 
despertar mass-media y filósofos, de un sueño cuyas largas repeticiones pesan. Si allí se dicen cosas importantes que me gustaría poder volver a decirlas con detalle — pero ¿para qué volver a copiar sus páginas?-, se añade allá la suave humildad de renunciar a designar demasiado pronto el lugar hacia el que converge esta multiplicidad de puntos de vista.

Como no participé en aquellas jornadas ¿puedo permitirme escribir aquí las intervenciones que, quizás, el colectivo reunido allá me hubiera permitido, y seguir paso a paso sus discursos? Mejor aún ¿cómo hubiera reaccionado si los que intervinieron hoy hubieran sido, en la época, mis predecesores? Finalmente confieso que este libro me concierne como autor del Contrato Natural y de la tetralogía del Gran Relato.

\section{Primera cuestión}

Para comenzar ¿cómo puede ser que, casi todos decididos a reformular el conjunto de las cuestiones de la democracia en términos ecológicos, para no decir cósmicos, esos expertos allí reunidos no han tenido en cuenta todo lo que entra en el biotopo: por supuesto que los humanos, y sobre todo su miseria, pero también los elementos, el agua, la tierra y la energía del fuego, más el conjunto de los vivos, especies de flora y de fauna, y sus interconexiones (no me gusta ese tic abiertamente antropocentrista de llamarlos no-humanos; ¿qué pensarían ustedes de mí si yo llamara no-franceses no solamente a mis amigos alemanes y aborígenes sino también a las libélulas y a los castaños?), para limitarse a la atmósfera, incluso tomada en plural, y al aire, incluso considerado como metáfora? ¿Hay algún secreto en esta elección? Además de los gritos de los que intervenían y de los hambrientos, esos filósofos, sociólogos, historiadores, antropólogos... ¿le estaban temiendo a los ríos y al océano, a las parcelas inflamadas que se desprenden de los pozos de petróleo, a las tierras silicoarcillosas batientes laborables y a las innumerables variedades que corren los mares y las selvas, como para solo necesitar inspiración? ¿Podemos adivinar sus razones?

\section{A la búsqueda del viento perdido}

Se trata pues, ante todo, y desde el título, de atmósferas. Concierne al especialista en la China en donde el viento sopla de todas partes, en el desierto y en la lengua, y al observador de los invernaderos con aire acondicionado. $\mathrm{Si}$ hubiera estado presente, creo que hubiera dicho que la metáfora del viento y de los soplos también Occidente la explotó como lo hacía la lengua china; no, él no la minimiza. Pues todos los días decimos: ¿qué aire tengo? para significar 
nuestra apariencia, así como nuestras emociones; ¿no ha debutado la divina Becasina al servicio de la Marquesa del Gran-Aire? En la campiña y en la playa bebemos una gran cantidad de aire, mientras que ostentamos en nuestro rostro un aire de grandeza o de timidez, de franqueza o de hipocresía... ¿No encontráis acaso a Cyrano y a Tartufo con un aire acondicionado? Y pienso ahora, ¿no encontráis así mismo, con el mismo aire bien condicionado, las cabezas de nuestros políticos, de nuestras vedettes mediáticas y públicas? Tenemos así una definición posible de las atmósferas de este libro.

Mejor aún, ese aire lo han visto y lo han pintado en sus telas nuestros grandes retratistas. Ningún maestro de antaño, ni Velásquez en el Prado, ni Vermeer ni Rembrandt en el Rijksmuseum de Ámsterdam, ni Watteau por los lados del Louvre (todavía invernaderos) ni Fra Angelico en el convento San Marco de Florencia... No les falta el halo alrededor de todos los rostros, ni el nimbo, ni la aureola para hacerlo ver, subrayándolo. Si no creéis en su existencia, acercad vuestra cara a la de un desconocido; ¿a partir de qué distancia quitará él la suya? Prueba de que una envoltura transparente viste o recubre a los dos. Circulando con la materialidad de una máscara, este aire individúa a los santos y a los bandidos, a los ángeles y a los diablos, reyes y camioneros; marca las distancias en las filas de espera.

Principio de individuación materializa el alma, el anima latina, salida ella misma de anemos, el viento de los griegos. Su pneuma espiritual, inflamos con él nuestros neumáticos. Antes incluso de todo ruagh hebraico, que sopla de lo alto de la trascendencia, el viento, en las lenguas de Occidente, hace vivir y personaliza, incluso a los animales, admirablemente nombrados. De él desciende el animismo, del que hablará Philippe Descola. Cuántas veces se ha dicho de mí, filósofo, que solo vendo viento, flatus vocis... Y un golpe más: nuestra psychè, significa primero ese viento, soplo y hálito; separada del cuerpo de los muertos, los griegos la materializaban como una expiración, venida (se decía) de los chamanes de Siberia. Ulises, Eneas, el propio Dante, todos los que descendieron a los Infiernos vieron a sus ancestros a través de esas sombras aéreas. Creer que esta metáfora de la buena brisa no moviliza las lenguas europeas equivale a olvidar lo que anteriormente se llamaba, y hasta hace poco, lo espiritual, término igual y completamente material, palabra precisa que decía que el espíritu sopla, tanto en la respiración pulmonar como en la inspiración del genio. Citados por François Jullien, los feng chinos se traducen pues en nuestras lenguas por el tic, tan frecuente antes, que consistía en evocar el nuevo espíritu científico, en buscar cómo el espíritu venía a las bellas, a considerar gravemente el espíritu de los pueblos o de las civilizaciones, e incluso el espíritu de las leyes... Un cierto viento griego soplaba en ráfagas entre nosotros. 
Aire del rostro y del espectáculo, aliento en el porta-voz de la máscara de actor llamado en latín persona, aureola o halo individuales, viento de alma, soplo de espíritu... Esto no ha acabado, pues aquí estamos bien precisamente: el libro por entero busca, con paciencia y tenacidad, lo que llama inteligentemente Las Atmósferas de la Política; por tanto, concretamente los aires, por tanto los vientos, por tanto los soplos aéreos, por tanto en griego, latín, italiano, inglés, francés... en suma en nuestras lenguas indo-europeas - ¿cómo en chino?-el poder espiritual. Esta última expresión, bien clásica, no hace sino traducir o decir - pero un poco de otra manera- el título mismo y ese desarrollo refinado sobre el viento. Reducir pues las cuestiones de política ecológica a la atmósfera, eliminando de ello la tierra, el agua, los vivientes y los cristales, haciendo callar también la tradición de nuestras lenguas sobre esta imagen, ¿equivale a decir que se trata de discutir, entre gentes inspiradas —eso se lee, eso se escucha, eso se ve y me alegra-, pero sin decirlo ni confesarlo, sobre el poder espiritual, tan difícil de concebir como de ejercer? ¿Habría pues yo adivinado?

\section{El final de los ulemas y de los intelectuales}

François Jullien prosigue, aclarando con magnificencia la ruina de los ulemas cuyo poder en tierras musulmanas, tenía que ver con el conocimiento del Corán y con el analfabetismo del pueblo. Consejeros de los poderosos, aquellos de los que se podía decir que constituían el alto clero, temperaban por una parte la tiranía posible de esos fuertes, mientras que, por la otra, el bajo clero trataba de apaciguar las revueltas posibles de las masas, también bajas. En resumen, tenían el poder espiritual. Desposeídos hoy de esa función por la expansión de la red, helos reemplazados por los extremistas que ponen cara de poseer una competencia sobre los textos sagrados, camuflando su ignorancia en discursos (dice él) tan encendidos como abscónditos.

Este exacto análisis deslumbra por la oblicua luz que lanza sobre Occidente, que precisamente acaba de conocer la misma derrota. Ciertamente, la Iglesia había perdido desde hace mucho tiempo el poder espiritual, pero ahora se le acaba de quitar a los intelectuales. iOh manes! de Diderot y de la Enciclopedia de las Luces, que predican la tolerancia, ioh manes! de Victor Hugo, que desafían al segundo emperador en su peña, en Manche, que atacan la pena de muerte y defienden a los Miserables; ioh manes! de Péguy que aportan el apoyo de su pluma polemista al servicio de Dreyfus; ioh nuestros ulemas perdidos!, reemplazados por el ruido y las imágenes irrisorias de la finanza y del espectáculo... Nuestros otros sabios, sociólogos, filósofos, poetas, artistas, a quienes las vedettes de los media precisamente les han robado el poder espiritual; los más inteligentes de entre nosotros reunidos en Venecia, buscando Atmósferas y esos alientos perdidos. 


\section{La lanza destrozada de San Giorgio}

Helos acá reunidos en una isla y bajo una cúpula rematada en una estatua de San Jorge que abate al dragón, pero cuya lanza rompió el rayo. Ellos reflexionan primero que todo sobre el sitio. Yo los imito. Hace bastante poco, y por razones que ignoro (pero que quiero adivinar) la Iglesia católica suprimió a san Jorge del calendario. Sin embargo, su símbolo instruía triplemente: santo, daba lugar a fiestas piadosas; guerrero, acorazado, armado hasta los dientes, combatía en el ejército; el nombre Jorge, finalmente, significa en griego, luego en latín, el campesino, héroe, en particular, de las Geórgicas de Virgilio. De acá la trinidad: religioso como Júpiter; soldado como Marte; bucólico como Quirinus.

Él solo resumía las viejas particiones de nuestras sociedades indo-europeas, siguiendo la intuición de Dumézil (cuyo nombre precisamente era George). Desde el neolítico, ninguna política podía instalarse, al menos en las latitudes europeas, sin tener una cuenta rigurosamente equilibrada entre el Clero, la Nobleza y el Tercer-Estado, cuya partición en clases y funciones se remonta a los tiempos inmemoriales cuando se soñaba un dios en los templos o en los bosques sagrados, un segundo dios en los campos de Marte y de batalla, un tercero en el pagus de los campesinos y de los paganos pacíficos o en la plaza del mercado. La efigie de San Jorge nos hace vivir y respirar en la atmósfera de nuestras antiguas y presentes políticas.

En el momento mismo en que, por una caída transhistórica del número de campesinos, la agricultura se hundía; en el momento en que la Europa de las naciones dejaba de suicidarse en guerras fratricidas y emprendía el olvido de sus fronteras... la partición mencionada se borró, sin que se pueda decir aún cuáles nuevas divisiones estructuraron los grupos por venir y dinamizaron su política. Consecuente, entonces la Iglesia borró el símbolo, único y estable, de esta vieja cartografía funcional y social. Finalmente, por un feliz azar (que se parecía a la necesidad) el rayo (ya lo he dicho) rompió el brazo del caballero que (colgado en la altura) blandía una lanza por encima del convento que lleva su nombre y donde se llevó a cabo la reunión del libro. Ya no está Jorge en el calendario; ya no hay ejército, al menos en esta parte de Europa; queda apenas un poco de campesinado. De lo alto de la cúpula de la isla San Giorgio, in hoc signo victo, la estatua tres veces vencida esperaba una delegación de los vencidos espirituales de la sociedad actual, disociada, pero aún no recompuesta.

Nada ya de Quirinus agrario; no más armas en el brazo de Marte; pero ¿qué con respecto a Júpiter? Y la misma pregunta regresa sin cesar. 


\section{Dos lamentaciones por la misma derrota}

Intelectuales, artistas, filósofos, religiosos, científicos, todos juntos, hemos perdido el poder espiritual en la actualidad en manos de los media, cuya alianza con la política transforma todo acontecimiento en escena espectacular, publicitaria, ruidosa, vacía y nula. Arrastrando al mundo entero, al que obligó por ejemplo a festejar la llegada del milenio el $1^{\circ}$ de enero de 2000 como si nadie supiera contar con sus dedos. En los siglos pasados, la fiesta siempre tuvo lugar en 1601, 1701, 1801... cuando la opinión escuchaba a los que saben calcular. La derrota de los sabios nos precipita en un siglo de Tinieblas, donde el mundo ni siquiera sabe contar hasta diez. Como por todas partes, aquí en Venecia el debate luminoso y secreto se desenvuelve sobre fondo negro.

Escucho pues un ruido de fondo real, mantenido a todo lo largo de esos diálogos, una música sostenida bajo los argumentos, una tonalidad baja entre las palabras. Escucho esta melopea: hemos perdido; lloramos nuestra vieja ciudad, nuestra política abandonada, el decline de nuestras culturas. Henos pues desencantados. De repente, de todo el libro, las más bellas páginas traducen en palabras directas, en frases leales, en confesiones musicales y poéticas... ese ruido de fondo desesperado. Escuchad entonces a Adam Zagajewski recitar dos equivalentes de las Lamentaciones de Jeremías, una griega, la otra polaca, las dos por las marchas de Europa, dos bellos poemas escritos bajo los peores gobiernos, como si la belleza naciese precisamente de esta derrota. ¿Cómo perder con dignidad? Oíd la lección: los que ganan saquean la apuesta porque obedecen, esclavos, las normas más bajas, las órdenes expresas innobles del gran número en procesión, mientras que el que pierde, frente a su propia derrota, descubre su persona, al mismo tiempo que su finitud.

Pero, dicho uno de los dos poemas y de nuevo como Jeremías ante Jerusalén ¿qué significa esta pérdida? Ante Alejandría, Antoine constata que los dioses lo habían abandonado. Ante Venecia, aún de pie, consolaos, oh filósofos, mis amigos, oh intelectuales derrotados como yo, vosotros merecéis Venecia como el héroe latino mereció la ciudad de Alejandro, mientras que los dioses nos han abandonado. Pero ahora pienso ¿quién perdió a quién en el asunto? ¿No hemos también abandonado a los dioses, puesto que ya ni siquiera logramos, entrabados de lengua, pronunciar la expresión: poder espiritual? ¿Quién nos ha vencido si no nosotros mismos?

A veces uno de vosotros lo confiesa; pero ¿a quién invitar a qué mesa para cuál negociación? ¿A la naturaleza misma para que firme con nosotros un contrato? Tiemblo pensando en las feroces críticas con las que se me agobió icuándo imaginé audacia semejante! ¿A quién invitar pues? ¿La estatua del 
Comendador, la de san Jorge desarmado? ¿Qué sombra vaga, qué prosopopeya, cuál dios? Voy pronto a regresar a esta mesa.

\section{La primera domesticación}

Pero antes: como nos quedan aún (acabo de decirlo) algunos andrajos geórgicos, y dado que por otra parte las discusiones allá en Venecia giraron en torno a una nueva política ligada al entorno, hablemos ahora de agricultura, en la muy larga duración. El cultivador hace nacer especies y variedades de flora; el pastor especies y variedades de fauna. Su trabajo común produce, en la granja, vivientes que, si permanecían salvajes no podrían nacer en la casa, sino solamente, como lo indica la palabra, en la naturaleza. Como también lo indica su nombre, estrictamente político, la natio, puramente humana, agrupa a los que en el pasado nacieron allá —natio, natus - salidos de genitores ya instalados allí; al asociar así el derecho del suelo con el derecho de sangre, ella se opone por una parte a la naturaleza - natus, natura - como el participio pasado al participio futuro del verbo nacer, y, por otra parte, a la familia, rural que agrupa granjeros, reses, arados, tierras y sirvientes, en latín famuli.

Desde hace algunos decenios pensamos las ciencias humanas, adosándonos para ello a la pareja cultura-naturaleza, bien reciente, inventada en Alemania en el siglo del Kulturkampf. Pero la había precedido la pareja gramatical nationatura, y otra rural: familia-natura. Como acabo de decirlo, la primera distingue el nacimiento pasado del porvenir; la segunda opone un grupo que comprende, aquí mismo, en esta granja, pegujales, algunos animales y algunos humanos, ligados por el suelo y la sangre... a otro, que agrupa los mismos elementos, pero tan general que se vuelve universal, mundial, cósmico. Recordemos de paso que el término política se restringe solo a designar homo sapiens, que vive en apartamentos o casas y que pasa apresurado por las calles y las plazas de una ciudad. Excepto en la India, más vacas; excepto algunos ramilletes, más flora.

\section{La segunda domesticación}

Cuando escuchaba a Renan gritar imilagro! para describir la emergencia de la ciencia en la Grecia del siglo V antes de Cristo, pensaba (y no me atrevía a decirlo) que solo se trataba de una segunda rareza; siempre había considerado la domesticación de algunas especies de flora y de fauna como una proeza sin igual, muy improbable en el proceso global de la hominización. Seguimos sin saber cómo hicieron nuestros ancestros para abandonar la caza o la recolección y volverse cultivadores. Amansar o domar es asunto que solo concierne a un individuo, a un espécimen, mientras que domesticar domina el tiempo 
milenario de la especie, bien precisamente ese nacimiento continuado, del que acabo de hablar. La oveja pare y las vacas crían, mientras que los otros animales no se reproducen en las casas construidas por los hombres; logro rarísimo de reproducción.

Cuando ahora releo la recomendación cartesiana: volverse "amo y poseedor de la naturaleza", de acá en adelante ya no la comprendo como la tradición me obligó a hacerlo. Esta dominación tiene un origen preciso que se lee en la palabra misma: domus, que significa acogida en la casa. Dominación, domesticación. Poseedor, propietario, señor, el dominus latino hacía entrar en la granja, en su lugar, en su locación, en su doméstico, en lo propio, los diversos elementos que la constituían en familia. Sin duda actuaba como un macho salvaje dominante que marca su nicho, pero, además, inventaba de hecho otro tipo de grupo distinto al de la natio, donde (la palabra misma lo dice) solo se reunían humanos nacidos, ya allá, de padres, ya allá. Por esto los ya citados: el derecho de suelo y el de sangre. En la familia, por el contrario, yerbas y bueyes, pagi o pegujales, arados también, se codean de acá en adelante con humanos, esclavos, sirvientes y niños. Descartes escribía pues como un cultivador habría hablado o actuado, del neolítico a la antigüedad, de los agrónomos latinos a Olivier de Serres. El filósofo sabio proyecta, simplemente, arrendar la naturaleza, domesticarla por entero y no solamente especies singulares, corderos y trigos. Se trata de un programa para el porvenir que consiste en querer hacer nacer en casa, en el futuro - natura - todo lo que nacía hoy en otra parte. El proyecto constante de la nación, el de la familia, sigue siendo el nacimiento. Pregunta: ¿cómo hacer nacer aquí mismo lo que no nace aquí?

Respuesta: construyendo nuevas casas. Sí, en este segundo acto, volvemos a construir. A la manera de los agricultores, los monjes recortarán, tras la abadía, jardines de simples; los naturalistas, más tarde, cultivaron jardines de aclimatación, concibieron zoológicos, dispusieron invernáculos... y henos acá en Peter Sloterdijk, pero también, un poco ien lo mío! Henos acá —digo yo- nuevamente, pero sobre el modelo antiguo, diez casas variadas para recibir pronto todos los reinos de flora y de fauna, compartimentos y cajas que generalizan campos, trojes, corrales, caballerizas y porquerizas, cuyos ocupantes, acogidos, solo nacen de especies raras, las que precisamente se dejan domesticar.

Y henos pues ahora yendo del Jardín de las Plantas hacia la Sorbona, y henos (digo) que aparecen otras diversas casas, ya no solamente para los vivos, sino para todas las cosas del mundo; los astrónomos elevarán cuadrantes solares, luego, después de Galileo, erigirán observatorios; los alquimistas construyen hornos; finos observadores abren, para sus colecciones, gabinetes de curio- 
sidades; los primeros físicos o químicos imaginan embriones de laboratorio. Mejor aún, a partir de Copérnico, Mercador y Vesalio, hacemos entrar los mapas de la tierra, de los mares y del firmamento, planchas de anatomía, en nuestras oficinas, en la casa; incluso los colgamos de los muros. El mundo entra a la casa. Las ciencias agrandan la granja; el zoológico amplía la cuadra o el corral; los invernaderos, los campos y el laboratorio, el taller. Considero pues el advenimiento progresivo de las ciencias como una segunda domesticación. No, ya no puedo ver las casas de sabiduría musulmanas, las academias antiguas y modernas, las universidades medievales, los campus contemporáneos... sino como granjas modeladas generalizadas donde los laboratorios agrandan las trojas. Mucho más tarde, quiero decir hoy, dominamos en las primeras la mutación, como dominamos en las segundas la selección. iTodas las cosas del mundo acaban pues de entrar en la casa!

¿Qué le ocurre en estas casas a estas especies y a esas cosas? Allí renacen. Aquellos animales, estas plantas, nacían en otra parte de otro modo en selvas oscuras y salvajes, no sabíamos cómo (algunos de nosotros incluso sospechábamos que ni siquiera nacían allá). Pronto vamos a realizar el sueño de esta época: hacer nacer, aquí mismo, en el laboratorio, toda la naturaleza. Desde el neolítico — cuando tuvo lugar el primer milagro— habíamos aprendido que la posibilidad o no de nacer en la casa distinguía a una especie salvaje de otra domesticable. Para lo mejor o para lo peor, el genio genético domesticará todas las especies llamadas naturales. En segundo lugar, aprendemos asimismo, que la experimentación debe poderse reproducir, que debemos poderla retomar a nuestro antojo, y que este renacimiento - descubierto o inventado en el Renacimiento- distingue precisamente un fenómeno en bruto de un hecho científico. Podemos indefinidamente hacerle nacer y renacer en la casa. Para las dos domesticaciones, funciones semejantes caracterizan lugares similares.

La asociación en familia se distingue de nuevo de la nación, donde vivíamos solos, porque lo que nace con nosotros, por medio de nosotros, en nuestro lugar o casa, se distingue de nosotros y se aproxima a nosotros entrando en casa. La llegada de lo que llamamos ciencia me parece incluso menos milagrosa que la primera, porque se funda simplemente en su generalización sistemática. No permanecemos en las especies domesticables, las que nacen fácilmente aquí, las que como nosotros (en nuestras naciones) siempre ya nacieron en el pasado. Vayamos atrevidamente hacia la naturaleza, hacia lo que quizás nacerá allí en el futuro.

Volvamos a leer ahora la expresión cartesiana; ciertamente que dominamos el mundo, pero como el dominus, como el antiguo dueño de casa o paterfamilias, seguramente mejor que él, pero sin embargo como él. Lo humanizamos como 
humanizamos el teosinte o el musmón para llegar a un maíz y a un cordero más fácil de hacerlo nacer; domesticamos los fenómenos mecánicos o físicos, los elementos y combinaciones químicas en laboratorios, como construimos pequeñas obras de albañilería agregadas a la finca para acoger allí a otros seres distintos de nosotros, como a veces los recibíamos en nuestra propia estancia.

\section{La tercera domesticación}

Y entran aquí ahora. Las hienas del Ngorongoro, los cocodrilos gigantes de Australia, el dosel de las selvas pluviales, lo que queda de los tigres de Bengala... acaban de penetrar hoy, en nuestra sala, por medio de las imágenes de televisión. Desde Pasteur y por intermediación de los monocelulares, cuyos reinos completan las antiguas clasificaciones (lo que en otra parte llamé la biocultura), entra no solamente en los laboratorios, sino en las farmacias y los muebles de nuestras habitaciones. Descubriendo el código genético, ella alfabetiza incluso las especies y, hablando su lenguaje, puede dominar la mutación, mientras que la primera domesticación solo dominaba, como ya lo he dicho, la selección. Tercera manera de conjugar el verbo nacer: la genética, sus clones y sus organismos modificados, su manera de inventar especies, su darwinismo tecnificado. Todos los vivientes, reales y virtuales, entran en la casa al menos virtualmente; tenemos todo el exterior adentro, todo lo salvaje domesticado, toda la selva encerrada en la hacienda.

¿Cuál casa? La granja generalizada, el invernadero generalizado de esta paisanería generalizada. Pues las aplicaciones técnicas de la segunda domesticación implicarán tales efluvios, que el planeta secreta en torno a él un techo general parecido al vidrio de larga duración que inventaron los ingenieros británicos y del que Peter Sloterdijk habla con tanto talento. Bajo ese palacio de cristal, invisible y sin fisura, reina el efecto invernadero, universal, que transforma al planeta entero en una sola casa, donde volens nolens, la humanidad modifica el clima. Ella habita de acá en adelante este invernáculo. No se trata ni de una ciudad, ni de la aldea global de la que MacLuhan hablaba hace poco, sino exactamente de una hacienda global donde, para lo mejor y para lo peor, arrastra consigo el destino de los vivientes y de las cosas del mundo. Sin dudar de ello, construyó su propia - lo propio de la propiedad (como lo he explicado en otra parte ${ }^{* *}$ ) al equivaler a la suciedad, la polución se vuelve la

\footnotetext{
** Se refiere a su libro El Mal propio [le Mal propre]/ lo Sucio [le Malpropre], ¿Polucionar para apropiarse? en el que se lee: "Por esto el teorema que se podría llamar de derecho natural —entiendo aquí por "natural" una conducta general entre las especies vivientes-: lo propio se adquiere y se conserva por lo sucio. Mejor aún: lo propio es lo ensuciado. La escupa ensucia la sopa, el logo el objeto, la firma la página: propiedad [propriété], limpieza [propreté], se trata del mismo combate pronunciado por la misma palabra, del mismo origen y del mismo sentido. La propiedad se marca, como el paso deja su huella". Traducido por Luis Alfonso Paláu Castaño, Medellín, diciembre de 2008, p. 3. Nota del traductor.
} 
firma de la apropiación - su propia, digo, vivienda mundial, donde los vientos y el calor que ella condicionó, introducen a esta era antropocena de la tercera domesticación. El efecto invernadero hace de la totalidad del mundo nuestra casa. Sucia, ciertamente, pero la nuestra propia. Antes incluso de ser firmado, el contrato natural se encuentra manchado.

\section{Resumen en tres variaciones sobre los invernaderos}

Naturalmente experimento la ternura por los invernaderos de Peter Sloterdijk; al punto de detenerme en ellos. Creo pues que la hominización se hace, al menos se hizo, a lo largo de estas tres domesticaciones. Estas consistirán en invitar a nuestras casas a vivientes distintos de los humanos, para formar con ellos y las cosas mismas, un grupo original. Tan original que aún no sabemos nombrarlo ni organizarlo en una nueva política, esa que precisamente buscan los genios de Venecia. Mientras que la ciudad solo reúne hombres, viejos, mujeres y niños en edificios dispuestos a lo largo de las calles en torno a plazas, mientras que esta ciudad dio lugar a la invención de lo que llamamos desde entonces política, por el nombre mismo de la ciudad y por exclusión de todo aquello que no lleva el nombre de hombre... la familia rural había inventado y continúa viviendo una especie de simbiosis original, un poco depredadora y parasitaria ciertamente, pero a vidas compartidas ya entre especies doblemente domesticables, perros y carneros que entran a la casa de los hombres, mientras que estos también entran recíprocamente en las moradas de los animales. A cada una de estas tres domesticaciones corresponden actos, grupos, individuos, relaciones, un espacio y hábitats bien definidos. Rápidamente retomo un resumen sucinto.

Luego de las novedades del neolítico, aparecieron progresivamente, en la primera domesticación, al lado de las construcciones donde vivía la familia, en el sentido latino, otros nichos, casas construidas para que allí morasen otras especies: la porqueriza para la cerda y el marrano, el corral para las gallinas y sus huevos, la caballeriza para las yeguas y los caballos castrados, el hórreo para los bueyes, el henil para el heno, el hangar para las gavillas, el campo para la viña y el trigo, el jardín para las frutas y legumbres... generalizo ingenuamente mi experiencia nativa, seguro de que la palabra domesticación evoca las variedades de hábitats propios para acoger una especie dada, imitando la alquería que frecuentan los humanos. En el comienzo pues, el dominio en el que, con los animales y las plantas domésticos, habita la familia de la que hablé.

Regresando sobre esas construcciones, quiero dedicar a los pensadores venecianos el recuerdo de una atmósfera comunitaria, de un aire del que 
poca gente en torno a mí guarda memoria, y hacerlos partícipes. No siendo suficientemente ricos como para construir esas obras especializadas en torno a la finca, la mayor parte de aquellos campesinos vivía (ya lo he dicho) en los mismos muros que las vacas. Bajo rigurosos climas, la respiración de las bestias, más su temperatura animal, actuaban como calefacción y, a veces, el heno y la paja de cama. En los años 1950 conocí entables levantados en zonas de pastos en los Alpes en el Queyras, del lado de Saint-Véran, donde se daba aún esta familiaridad. Acá tenemos el primer invernadero; el primer aire acondicionado está aquí; y además la primera comunidad donde se reúnen humanos, cosas y animales. El antiguo sentido de la palabra familia designa a este grupo, donde todos juntos respiraban la misma atmósfera, tibia y perfumada, de estiércol.

Más atrás aún, pero solamente en nuestra historia, muchos fragmentos, canónicos o apócrifos, de uno de nuestros antiguos Grandes Relatos, cuentan también que, al no encontrar sitio en el hospedaje, María dio a luz un hijo en un pesebre, donde un asno y un buey calentaron al niño con el soplo de su hocico, mientras que entraban allí pastores con ovejas y tres reyes que portaban mirra; ¿por qué Mateo añadiría que esos magos siguieron un astro que de repente se detuvo en el lugar donde estaba el niño, sino para convocar allí todas las cosas del mundo? Para que perdure en nosotros durante todo el tiempo esta imagen (que se volvió ritual) de la familia — ancestral a la vez que moderna puesto que adoptiva- ¿no fue necesario que san Francisco de Asís, "troubador" de las Fioretti, de los pájaros y del lobo, hubiera sabido despertar, conmemorándolo, algún recuerdo inolvidable de una antigua experiencia y de la comunidad original que reunió aquella noche a hombres, mujeres, niños, animales, paja y astros?

Tenemos acá invernaderos en tres memorias: personal, colectiva y religiosa.

\section{El invernadero de Pentecostés}

Detenido en lo religioso, aprovecho la ocasión para describir otro, menos rural, menos familiar y más político (en el sentido de citadino). Antes de que la técnica británica del vidrio de larga duración lo construyera para las plantas, pero luego de que la domesticación arrastró animales y cosas con los hombres a la misma casa caliente, la construcción —al menos virtual— de un invernadero cuasi político - al menos eclesial — había tenido ya lugar antaño, luego de la Navidad de Belén, en Jerusalén, el día de Pentecostés. En un lugar cerrado donde los apóstoles se reunían para celebrar la fiesta en que los judíos conmemoran la entrega que Dios hizo a Moisés de las Tablas de la Ley, en la cima abierta de la montaña del Sinaí, "se produjo de repente un ruido como el de 
un viento impetuoso, que invadió toda la casa en que residían. Aparecieron, como divididas, lenguas de fuego, que se posaron sobre cada uno de ellos". Viento más llama igual aire acondicionado.

"Quedaron todos llenos del Espíritu Santo; y comenzaron a hablar en lenguas extrañas". Corrida la voz de lo que acontecía se juntó una muchedumbre afuera en la que todos se encontraban estupefactos "al oírlos hablar cada uno en su propia lengua"; partos, medos, elamitas, mesopotámicos, los de Judea o de Capadocia, los del Ponto y Asia, Frigia y Panfilia, Egipto y Libia, emigrados de Roma, judíos y prosélitos, cretenses y árabes... he copiado la lista dada por los Hechos de los Apóstoles ${ }^{* * *}$ para mostrar hasta qué punto nuestros tropiezos de lengua (para utilizar la expresión de Bruno Latour) obstaculizaban también a los inmigrantes diversos del primer siglo de nuestra era, y en las mismas condiciones de asamblea reunida para entenderse.

Este genio de hablar en lenguas, este milagro de traducción instantánea consiste en dar acceso inmediatamente a un universal propio para reunir a los que se convocaban en la época de las naciones, es decir, a los goyim o gentiles. Se ve cómo la solución consiste en crear un invernadero, en el sentido de Peter Sloterdijk, una pieza cerrada, más que una cima abierta al cielo como la cumbre del Sinaí, un viento que allí se expande, una atmósfera que la llena, un calor emitido por lenguas de fuego, en suma: un aire acondicionado propio para hacer posibles el nacimiento y el crecimiento de los que no nacieron aquí, sino bajo otro clima, panfilianos, cretenses o árabes, más un ruido de fondo propio para que todos puedan hablar juntos. Por supuesto que se trata acá de un milagro, de una facilidad imaginaria; pero esto muestra la antigüedad tranquilizadora de un problema cautivante: en efecto, ¿qué hay más resistente, y durante más tiempo, universal, que las barreras colocadas por las lenguas vernáculas? Además, judíos y cristianos, de un Pentecostés al otro, se pasa de lo escrito (en las Tablas de la Ley) a lo oral y a los discursos de traducción simultánea. ¿Quién inventará la traducción instantánea automática?

De donde, regresando a Venecia, estas discusiones extremas, por supuesto orales, sobre la forma de la mesa - ¿la del refectorio, la de la Cena o de la comunión, donde, antes de hablar, donde, en lugar de hablar, donde, lejos de hablar... se come? - en torno a la cual reunir a los que incluso obstinadamente se rehúsan a discutir. De repente pienso: si alguien os invita a sentaros en la mesa, no os exige forzosamente hablar; comed pues juntos platos simples y universales.

${ }^{* \star *}$ Hch. 1:11. (Edición BAC). Nota del traductor. 
¿Cuándo regresará Pentecostés y cómo? ¿Qué concilio, bajo la bóveda de Venecia, y para cuál nueva Iglesia? Y entonces regresa el poder espiritual.

Salid ahora, observad la bóveda celeste de noche - entre las que ama Peter Sloterdijk y que el propio Moisés podía ver del Sinaí, pero que los apóstoles apenas apercibían desde su sala cerrada-; allí brillan Antares \& Arcturus, con nombres griegos, Betelgeuse \& Rigel, con denominaciones árabes, Orión \& Sirius, todas latinas; las lenguas de comunicación, las que no cesarán de sucederse en la historia, se dan cita, en paz, en el firmamento. Bajo el invernadero del cielo, los astrónomos y sus sucesores han intentado el golpe de Pentecostés. A menudo las ciencias hablan así en lenguas: las de Linneo, de la química, del álgebra o de las constelaciones.

Había dejado por un momento los movimientos de domesticación; ahora regreso. Al primero le seguirá la era científica: ya lo he dicho, el Jardín de las Plantas, el zoológico y el Museo de historia natural. De regreso de expediciones lejanas, los que se llamaron los naturalistas, inventaron nuevos museos, otros laboratorios. La ciencia moderna se lanza a esta segunda domesticación. Dirigida esta vez a las especies llamadas salvajes, ella hace que bifurque la actividad de construir. Los campos cultivados donde Flora crecía, los jardines y parques destinados a Pomona, van a ser seguidos por invernaderos de naranjos y de otras especies, donde un aire acondicionado permite a las plantas exóticas aclimatarse, más o menos, a las altas latitudes de Occidente. Peter Sloterdijk habla de ello sabiamente. Asimismo, acuarios de vidrio aclimatarán peces de los mares tropicales. Y la casa de fieras aprisionará leones y tigres, mientras que, bajo rejas y detrás de fosas, jirafas y monos hacen la alegría de los espectadores infantiles.

¿Quién habita en la casa, quiero decir en esos hábitats? En el primer período de esta historia serán plantas y animales domesticables reunidos en compañía de aquellos que los latinos agrupaban bajo la denominación de familia, que comprendía (como acabo de decirlo) bajo la autoridad del paterfamilias, la tribu en el sentido de la sangre, más los sirvientes, famuli, los esclavos, el rebaño y las herramientas, paja y aves. Ese grupo rústico inventa allá, ese agrupamiento original que he mencionado, que la política ignoró, rechazó e ignora aún hoy, con el que sueña sin duda sin saber que de allá vino; la polis, lo repito, solo comprende humanos, mientras que la familia en la que nos acostamos con las vacas acoge en la casa a otras especies vivas y las cosas del mundo.

En una segunda época, nueva acogida, en una recuperación aguda de un agrupamiento distinto al estrictamente político; entonces, salvajes o exóticos, especímenes - palabra bien exacta, expresada por Isabelle Stengers, palabra 
que designa individuos que cada uno representa una especie- se encuentran reunidos para el estudio y la exhibición en compañía de científicos ad hoc. Campesinos mezclados con reses y trigo, por una parte; por la otra, naturalistas mezclados con cobras y palmeras. A la primera domesticación corresponden nacimientos continuos en una especie que vive en la casa, mientras que los especímenes salvajes no se reproducen aquí. A la primera corresponde la selección de vivos domesticados, a la segunda responde la selección científica de humanos estampillados con diplomas, viajes y exámenes periciales; especialista, otro término para espécimen.

Además, debo anotar que la primera domesticación destruía, en un lugar dado, lo que se llama hoy la diversidad cultural. Los nuevos labrantíos mataron todas las especies distintas a las que se deseaba cultivar. Aquí, nada de trigo o de arroz, pero igualmente en el corral solamente aves, en el aprisco solo ovejas, que este encierro protege de los zorros y los lobos. La segunda domesticación perpetúa esta elección; el estudio de las especies no las pone en relación, las escogencias de los especímenes los aíslan, los clasifica y los yuxtapone. Así, el zoológico no innova sobre la troj, ni el jardín de plantas sobre el campo, excepto que se fracase en el nacimiento y salvo el invernadero para el entorno. Me place decir, finalmente, que la escuela y la universidad, en este segundo estadio, destruyen así mismo la diversidad humana e incluso cultural, seleccionando sus hombrecitos, encerrándolos, como la agricultura hace con los gallos, las manzanas y los puercos. Estos son nuestros chicos domesticados.

La verdadera revolución interviene en el tercer estadio, en la actualidad.

\section{Los Parques}

Pues vivimos una tercera domesticación. Abiertos como ellos, menos construidos y menos cerrados que ellos, los Parques - de Yellowstone, de los Pirineos, montañeros o marítimos...- suceden a la hacienda y al zoológico, a la selva, a los campos y a los jardines de las dos primeras domesticaciones, al mismo tiempo que se oponen totalmente a ellos, al mismo tiempo que inventan novedades radicales. Ya no más reja, ni vidrio, ni muros. La mezcla toma todo el lugar, termina la separación. Lado fauna y flora, lado tierra y agua, se renuncia a las especies como tales, elegidas por ejemplo por su facultad de nacer en la casa; así mismo, se deja a los especímenes como tales, antaño seleccionados por la clasificación y el conocimiento; de acá en adelante, se considera a la comunidad de los vivientes y de las cosas tal cual en un biotopo dado; por el lado humano, se renuncia a la familia y a la comunidad científica, para considerar la política de los hombres tal cual, en un biotopo análogo. Primero, pocas especies 
seleccionadas habitan con pocos humanos nacidos de un mismo ancestro; luego, muchas especies salvajes, pero en estado de especímenes agrupados con muchos humanos de una especie seleccionada por su especialidad; todas las especies finalmente, en un perímetro abierto, cohabitando con todos los hombres y todas las mujeres de una política dada. Primer grupo: familiaespecies domesticables; segundo agrupamiento: naturalistas-especímenes salvajes; tercera agrupación asocia las interrelaciones humanas en la política con las interrelaciones ecológicas en el entorno. El Parque se vuelve entonces el hábitat de esta ecología política, como el Museo de Historia Natural es el de las ciencias del viviente, y la finca la casa de la Agricultura. A cada domesticación corresponde una variedad de casas, una variedad de agrupaciones, de acciones, de relaciones, de saberes y de prácticas.

De paso no olvidemos distinguir dos sentidos, bien diferentes, de la ecología. Cuando conquista recientemente la escena política se la ha definido (bastante mal mientras tanto) como protección de la naturaleza; la etimología del verbo proteger ¿nos comprometería a lanzar un techo por encima de ella con miras a preservarla? Seguramente que hemos logrado este prodigio, pero iay!, a contrasentido; temible y transparente, ese techo se llama iefecto invernadero! Pero antes de entrar en esta arena espectacular, la ecología nació — hacia finales del siglo XIX, en Madison, Wisconsin, y en Montpellier, Francia- como la ciencia, composite $^{* * * *}$ y bien difícil, de las interacciones entre todos los vivientes en un lugar bien definido - la montaña solitaria del Ventoso en Francia, y las altas latitudes lacustres en los Estados Unidos de América-. Ella desarrolló una descripción matemática, física y bioquímica compleja de esos trenzados. Estos dos sentidos conciernen hoy a dos poblaciones que, frecuentemente, iay!, no se comunican. Ahora bien, esta ciencia nueva y trascendente, no hizo y no produce aún revolución más que por tener esencialmente por objeto esas interrelaciones. Por esto acabo de insistir sobre la novedad del Parque, a título del lugar donde se juegan, nuevamente, a plenitud las interacciones de los sujetos políticos entre ellos interactuando con las interacciones de los vivientes y de los objetos inertes entre ellos.

Dándole la espalda a la política exclusiva de la polis, incluso de la nación, la ecología política, actualmente observada en los parques, conserva ciertamente tipos de agrupamientos inspirados en la familia, en el sentido latino, en la finca o en el invernadero, pero ella suma acá una realidad a la que las precedentes no sabían ni podían acceder, porque ellas escogían o elegían

\footnotetext{
Composite (nombre masculino). Material muy resistente constituido por fibras de vidrio, de carbono, de boro o de cerámica que se emplea principalmente en la industria aeronáutica y espacial, en la fabricación de material deportivo, como raquetas y esquíes, y de prótesis dentales. La palabra es aquí usada de manera figurada. Nota del traductor.
} 
especies o especímenes (que era como decir la misma cosa). Esta realidad, lo repito, concierne a las relaciones múltiples que mantienen en un lugar dado todos los humanos por una parte y, por la otra, todas las cosas del mundo. El múltiple enrejado de las relaciones en el conjunto o el sistema ecológico, imita, acompaña, habita la cuadrícula múltiple de las relaciones en el conjunto o el grupo de antaño únicamente político. ¿Cómo definir el Parque sino como el espacio abierto, la nueva casa, la sede, el hábitat, la imagen y la realización de esta recíproca intrincación?

Como no conocemos todavía ninguna institución que se haya encargado de tal mezcla, a la vez arcaica y nueva, nos vemos obligados a considerar el Parque como un modelo reducido posible de nuestra relación futura con el planeta entero, en suma: de la política — sería menester encontrar otra palabra- por venir. En este sentido, el parque figura como proyecto. Nos muestra el porvenir de los hombres y del mundo. Aquí, la hominización misma está en juego.

\section{Revolución cognitiva ligada a la caída de las paredes de vidrio}

Hace un rato hablé de las murallas en la granja y de paredes traslúcidas en los invernaderos y los acuarios; vuelvo sobre ello un momento. En las afueras de Alice Springs, en el centro del outback australiano, usted puede (en el interior de un Museo tan transparente y aéreo que creerá estar caminando en el exterior) visitar la flora y la fauna de desierto en el desierto mismo. Las puede observar a través de una pared de vidrio, que se colocó simplemente para indicarle qué es lo que tiene para ver. El vidrio del invernadero se ha dado vuelta; no se curva para encerrar las cosas en su clausura; plano, puede, también y, por el contrario, encontrarse rodeado por ellas y por nosotros; incluso se lo puede suprimir sin inconveniente. El vidrio del invernadero rodeaba, delimitaba, definía, encerraba las plantas y los animales... y conducía ihacia los conceptos! Aquí liberados — ¿cómo definir mejor una democracia que por la libertad? — viven como lo entienden, y usted los mira como los entiende. Seguro que se comprende esta inversión como una liberación real de los animales, pero también como un nuevo acto cognitivo; objetos que yacen dentro de cajas, objetivados como en conceptos delimitados por ellas; si usted abre la caja ¿siguen siendo objetos?

Pasa lo mismo con los acuarios. De Nápoles a Mónaco, de París a Monterrey, admirábamos lo mismo y desde siempre las evoluciones de peces diversamente coloreadas a través de cajas o bocales de vidrio; ahora bien, su pared se volteó siguiendo la misma revolución que la de Alice Springs, y que me encantaría llamar ptolemaica, de tal suerte que nuestra visita pasa de ahora en adelante, en Sídney por ejemplo, a través de corredores de vidrio transparente que nos conducen, nos encierran a nosotros, mientras que tibu- 
rones, pulpos y rayas nadan libremente en el volumen de la bahía, entre las algas flexibles y la escultura contorneada de los moluscos pegados a las rocas de las profundidades.

En el segundo acto de la domesticación descrito hace poco, las paredes de vidrio rodeaban con su redondez a especímenes salvajes o, mejor aún, los definían como objetos de ciencia al mismo tiempo que se propiciaba un espectáculo para la mirada de los humanos. La esfera de vidrio del invernadero o del acuario reparte, en efecto, cada uno en un lugar cerrado, como un subconjunto, como un campo semántico — vamos incluso a verlo: como un concepto— como si objetivase cosas, lanzando así objetos delante de un sujeto; construían la escena cognitiva antigua que el llamado sujeto se daba de esos objetos. Esta escena del conocer repetía bastante fielmente las del cultivo o de la crianza que encerraba las gallinas en el corral, el trigo en los campos, los manzanos en el jardín y los marranos en la porqueriza. ¿Os escandalizaría si definiese, como acabo de prometerlo, un concepto en su extensión y su comprensión, como el correspondiente formal, el heredero o el descendiente blando de ese campo cerrado, de esa granja, de ese jardín él también cerrado, de esa troj con especímenes rumiantes, de esa porqueriza rodeada de planchas, todos duros? El conocimiento imita, repite, afina... a la domesticación, formalizando gestos y prácticas análogas, construyendo semejantes hechos en bucle. Domesticamos también a las pequeñas y a los pequeños en la escuela, lo he dicho, y las obras de genio en los museos; los apilamos y los comparamos, los emasculamos.

Y de pronto, a la inversa, estamos en el tercer estadio: una decisión colectiva (que se puede llamar política puesto que la tomaron los expertos científicos y la opinión pública ya mejor instruidos los dos), una decisión colectiva, digo, deja fauna y flora o peces evolucionar juntos o solitarios, en sus nichos y su cadena alimenticia, los deja pues a sus relaciones y a su entorno colectivo, en suma, a su ecología, quiero decir a sus interacciones. Esto es lo que significa para el saber y el mundo la frase de hace un rato: nada de muros ni de paredes, no más piedra ni más vidrio, terminó la separación. Alimentaria o de crianza, cognitiva, de epistemología o de filosofía, la vieja asimetría sujeto-objeto se borra en provecho de un entrecruzamiento recíproco de relaciones. No se trata de reemplazar una asimetría por otra, sino de una ruptura de toda asimetría. Grupos escolares, buses llenos de turistas, gentes que hacen tesis... se muestran los unos a los otros como masas vivientes, bancos de peces; los pescadores y los cazadores, los consumidores, los ecologistas y los políticos, mantienen relaciones evolutivas entre ellos y con el desierto o la bahía, según la evolución del biotopo, observado desde esos nuevos corredores. 
Generalizando estos modelos reducidos de Museos o de acuarios, regresemos al Parque donde, en una amplia escala, poblaciones de guardias y de turistas, de científicos y de pastores, incluso las de la opinión pública... mantienen relaciones que se mezclan, abiertas, con aquellas, igualmente complejas, que mantienen cosas y vivientes. El saber y las prácticas, incluso la política, se reúnen con el mundo tal cual. No exageraba para nada cuando hace un rato decía que se trataba de un momento decisivo de la hominización; en efecto, ya no se trata de las mismas relaciones entre nosotros ni con el mundo ni con el conocimiento. Ya no se trata del mismo mundo ni del mismo conocimiento.

\section{El viejo parásito, el nuevo simbionte}

Habiendo abandonado tanto la familia en el sentido rural como la comunidad científica clásica, renunciamos de aquí en adelante al estatuto exclusivo de sujetos. Nos mezclamos. Avanzamos en una idea nueva de democracia, donde otros distintos de nosotros se sienten acogidos; pero de una forma distinta a la troja o al zoo, de un modo distinto al bocal y al invernadero. Ya no los encerramos al momento de invitarlos. Nadie interviene, ni ellos sobre nosotros ni nosotros sobre ellos, dejando a cada quien libre de sus relaciones e inventando relaciones entre esas dos redes. De repente, este tercer estadio lanza, como de rebote, una luz viva sobre nuestras viejas costumbres, de la época aún iay! viva, de la segunda. La vieja asimetría cognitiva por la cual recortábamos, rodeábamos, en rigor definíamos, de hecho, aprisionábamos, aquí por medio de una frontera de vidrio, allá por medio de paredes, muros, fosas o conceptos... a los objetos, con miras al conocimiento o al beneficio de sujetos exclusivamente humanos, nos colocaba en posición de parásitos.

Les quitábamos todo a los otros y no les dejábamos nada, mientras que ellos nos daban todo y no nos exigían nada. La tradición jurídica llama a esto un contrato leonino; tengo derecho a todas las partes puesto que me llamo León. Totalitario, egocéntrico, colonizador de la naturaleza entera, los viejos fabulistas Esopo, Fedro y La Fontaine, habían llamado ya así al hombre. En la cima de la cadena alimenticia reinaba un depredador universal, quiero decir, él mismo libre de todo depredador. Nuestro conocimiento, nuestra ciencia, nuestras propiedades exclusivas, nuestras actividades sin pasividad, nuestras tomas sin intercambio seguían siendo de naturaleza depredadora o parásita. Entonces, el tercer estadio reforma nuestras ciencias, nuestro conocimiento, nuestras prácticas y trabajos, en fin y, sobre todo: nuestra razón; ya no arrasaremos las cosas del mundo. Ellas y nosotros somos sujetos-objetos todo a la vez. Juntos, acabamos de firmar el contrato natural. 


\section{Los guardias de la nueva República}

Finalmente quiero presentaros los guardias de un parque, el de los Pirineos, por ejemplo, gentes excelentes con las que he caminado, comido, velado, trepado, sudado... que me han instruido, que he admirado. Antiguos campesinos, primero, cuidan de memoria la conducta de los que lograron la primera domesticación; por tanto, como yo, cercanos a los cultivadores y a los pastores; pero, como yo, ya no practican la paisanería; no cosechan, ni siembran, ni ordeñan, pues se volvieron guías, parecidos a los que me conducirán a la alta montaña, es decir predecesores, salvadores y pedagogos. Vueltos sabios, guardan de memoria la conducta de los que lograron la segunda domesticación, pero ya no viven como hombres de gabinete, como antiguos observadores que triaban, extraían, recortaban objetos singulares, especies o especímenes, pues promueven una ciencia nueva que tiene el cuidado de dejar las cosas tal cuales en su estado, para notar, con la paciente lentitud de lo inerte y de lo viviente, sus relaciones evolutivas; piensan y actúan finalmente como hombres y mujeres de sociedad, advertidos de las ciencias humanas, del derecho y de la política... pero no, aquí me equivoco y debo recomenzar; tenemos acá mujeres y hombres que esperan, como yo, construir nuevas ciencias humanas y, como yo, pensar un nuevo derecho, aplicar un nuevo contrato que se lo podría llamar natural, creando pues un nuevo tipo de agrupamiento donde se trataría de tejerle a las antiguas relaciones exclusivamente humanas, por tanto llamadas aún políticas, las relaciones reales del entorno. Siguiendo la más venerable de las tradiciones filosóficas, los llamaría con gusto Tejedores democráticos.

Los guardianes del Parque, mis hermanos, enlazan pues en ellos las tres domesticaciones bajo las luces tímidas, aunque brillantes, de la noticia. En ellos, veo los padres de los que mañana intentarán renovar la cara del planeta a imagen de su Parque. Inventan hoy hilos, de los que yo querría que me enseñaran la materia propia para tejer la trama arlequín de nuestras diferencias humanas con la cadena abigarrada del entorno.

Amigos, enseñadme vuestra nueva lanzadera.

\section{Eutopía}

Por ejemplo, la asociación de humanos, de vivientes y de objetos requerida hoy por y para el contrato natural, retoma la familia latina y la granja rústica, en una paisanería generalizada bajo especies globales, sub specie mundi.

Espacio abierto a las interconexiones libres en el cual aprender a vivir una nueva humanidad, el Parque a mi manera de ver, comienza a cambiar el 
estatuto de las ciencias, de los conocimientos y de la razón; los científicos ya se están dando cuenta de ello. Él enseña a cambiar la vida y nuestras conductas; nuestros contemporáneos lo experimentan, una opinión mundial emerge incluso sobre este punto. Ayuda a cambiar el derecho; los juristas preparan uno nuevo. Sobre todo: muestra un cambio mayor de la política; cuando, por haberlo aprendido, la vieja política abandonará finalmente el espectáculo que en alianza con los media nos ofrece para adormecernos, ¿será demasiado tarde? ¿El efecto invernadero habrá montado el techo invisible de una casa global para una trágica domesticación? Modelo reducido del nuevo mundo, el Parque muestra, ilustra, realiza, comienza otro, sin fronteras. Entrado ya en el porvenir, indica otra política. Por no querer extender su ejemplo al planeta entero, los poderosos hominescentes, temblando de infinitud ¿destruirán valles, planicies y montañas, frágiles de finitud?

Alguien llamó antaño Utopía a una isla administrada por un gobierno tan razonable que se la juzgó inencontrable en el espacio y en el tiempo. Propongo para el Parque, bien real, bien vivo, bien gestionado, el feliz nombre de Eutopía. Ahora las lamentaciones: hubiera sido necesario que un partido de guardias, venidos de Yellowstone, de los Pirineos, del Yosemite o del Mercantur, interviniesen en Venecia, en lugar de aquellos que tuvieron que expulsar los carabineros.

Los expulsaron a gritos y manu militari: ifuera! Pregunta: ¿qué hacer cuando comience el Parque donde ya no hay un afuera?

\section{Fuera de casa}

Bruno Latour pregunta: ¿dónde estaban los microbios antes de Pasteur? Respuesta: afuera, en la selva; afuera del domo de san Jorge, fuera del invernadero, fuera de la hacienda, fuera de la domesticación, allá donde los carabinieri precipitan a los intervinientes. Los microbios, las especies desconocidas, los fenómenos ante todo descubiertos, la ignorancia en general... vagabundeaban como salvajes, como el maíz en estado de teosinte y como las reses cuando eran uros. Salvajes ¿cómo nacen? Naturalmente quiero decir afuera, quiero decir más tarde, en participio pasado; no sabremos cómo nacen sino cuando nazcan en la casa. Domesticados, renacen a su antojo, en la casa, adentro.

Erraban por fuera de la casa o, como dice Maupassant, horla «hors-là = fuera de acá». De ahora en adelante, están acá, como nosotros, dasein. Están aquí mismo. Vivían afuera, en la selva "forêt" — fuera de "fors", afuera "dehors"— de donde eran expulsados; o echados fuera de la casa, es decir, excluidos como los 
que protestaron en Venecia; o bien perseguidos por los cazadores-recolectores, por los domesticadores, por los científicos conocedores. Corrían por los espacios vagos del no-derecho, con los abandonados, los despedidos, los excluidos, los sin domicilio, los miserables, los asesinos, los recapturados por la justicia... Visitan la casa ahora o, en rigor, el fórum, la plaza política. Los hicimos pasar de la selva al fórum, del Horlà hacia el Ser-allí, de la floresta por donde erraba la Loba-Vestal a los muros construidos por Rómulo. En efecto, solo teníamos una experiencia salvaje de los microbios: epidemias e infecciones, peste de Atenas o viruela americana; desconocidos surgen, surgen aún de la cintura forestal y tropical.

Oponiendo la casa interior al bosque exterior, la domesticación conecta realismo e idealismo, el primero jurando que las cosas existen como tales, antes de que sean denominadas y pensadas, el segundo pretendiendo que no hay ningún camello en el desierto hasta que los beduinos no pasen para verlo; el dromedario solo existe cuando llegue el primer beduino; lo hace existir, lo hace nacer, lo domestica. En el outback australiano, pululan los camellos marrones; ya nadie controla el nacimiento de esos animales que se han vuelto nuevamente salvajes. Salidos bruscamente del bush, provocan los peores accidentes de camiones.

Y aquí pienso: y nosotros, humanos cultivados, peor: domesticados, politizados, ¿dónde estábamos antes de la Ciudad, antes de la Política, antes del Derecho Romano, antes de la fundación de Roma, antes de Rómulo y la muerte de Remo? Tito Livio dice: bajo la loba, en el bosque; fuera, afuera, con las putas y los presidiarios; con Rhea Sylvia, la vestal forestal. Es tanto como decir: en el arrabal "banlieue» en los lugares de destierro "lieux de ban, bannissement». Antes de la fundación de la ciudad, antes de esta domesticación ¿quién los miraba? Por ejemplo: la historia excluye las civilizaciones sin escritura; ifuera! Los salvajes: ia la selva! Los más pobres: ia las comunas! Los contestatarios: ifuera del domo! iOh! amigos reunidos en Venecia, ¿por qué nunca habéis hablado de los pobres?

Todo lo que sabemos, todo lo que recibimos, acogemos, todos nuestros anfitriones... vienen del fondo de la selva, del fondo del mar, del desierto o de la morena, del fondo de nuestra ignorancia, del fondo del ruido de fondo. Ahora bien, no cesamos de deforestar, de sobre pescar, de hacer fundir los glaciales, de polucionar los océanos, solo comprendemos nuestras lenguas, nuestras músicas y nuestros sonidos, encantados solamente por nosotros mismos. No dejamos de hacer de la naturaleza nuestra casa. No dejamos de hacerla nacer adentro, bajo el efecto invernadero. ¿De dónde vendrán pronto nuestros 
huéspedes, de dónde vendrá nuestro saber? iSalvemos la selva, salvemos el no-saber! Salvemos pues a los miserables.

Incluidas las ciencias, comprendo la hominización como una domesticación continuada. ¿Hay un límite a esta domesticación, a esta dominación? Gran pregunta. Todo no vive aún dentro de la casa, ni mucho menos; decenas de millares de especies no empadronadas aún vagan por selvas o mares, en la primitividad del afuera; ¿cuántos insectos y monocelulares aún desconocidos? La materia negra parece ocupar casi por entero el universo; no sabemos lo que acontece antes de la barrera de Planck; todo eso yace fuera. En la selva, en el mar, en lo oscuro, disuelto en el ruido de fondo. La mayoría de los humanos muere de sed y de hambre.

¿No deben nuestros saberes hacer la misma revolución que vemos llevarse a cabo en el Parque? Este se voltea, invierte el conjunto de los procesos de domesticación; deja libre el juego de las interrelaciones, las nuestras, las de las cosas y las de los animales, más las que vuelven a ligar las nuestras y las otras. ¿Qué rostro, qué perfil tendrá la ciencia cuando (a imitación del Parque) ya no verá diferencia entre los sujetos y los objetos, entre el adentro y el afuera, cuando ya no tenga un exterior al cual mandar a los contestatarios de Venecia?

Cuando los científicos acojan a los miserables. 